\title{
RECASTING THE DYNAMICS OF POST-ACQUISITION INTEGRATION: AN EMBEDDEDNESS PERSPECTIVE
}

\author{
Audrey Rouzies \\ Toulouse School of Management - University of Toulouse Capitole \\ TSM Research -CNRS 5303 \\ 2 rue du Doyen Gabriel Marty \\ 31042 Toulouse - FRANCE \\ Audrey.rouzies@tsm-education.fr \\ $+33561635657$ \\ Helene Loe Colman \\ BI Norwegian Business School \\ NO-0442 \\ Olso - NORWAY \\ Helene.L.Colman@bi.no \\ $+4746410462$
}

\section{Duncan Angwin}

Centre for Strategic Management

Lancaster University Management School

Lancaster University

Bailrigg, Lancaster LA1 4YX- ENGLAND (UK)

d.n.angwin@lancaster.ac.uk

$+01524595167$ 


\title{
RECASTING THE DYNAMICS OF POST-ACQUISITION INTEGRATION: AN EMBEDDEDNESS PERSPECTIVE
}

\begin{abstract}
M\&A scholars have generally assumed that post-acquisition integration is a self-contained process. However this ignores that this process rarely unfolds as the only ongoing initiative in an organization. We contend that post-acquisition integration is not detached from other simultaneous change processes in the organizational context and this has important implications for our understanding of how integration dynamics actually evolve. To further understand this embeddedness we examine the unfolding of a post-acquisition integration process in a company faced with an unanticipated drop in demand due to the global economic crisis. Through a qualitative, longitudinal study conducted over three years, we carried out 151 interviews to uncover the unfolding of the post-acquisition process. We find that post-acquisition integration is embedded in a set of co-evolving processes. We highlight four mechanisms (coordination, cohesion, disconnection, alienation) that arise from the co-evolution of processes that either facilitate or impede integration. Our findings contribute to our understanding of postacquisition integration dynamics by recasting the integration process as embedded in a set of co-evolving processes that shape its unfolding.
\end{abstract}




\section{INTRODUCTION}

Post-acquisition integration is critical for reaping the expected benefits of the deal, harvesting synergies and creating value (Haspeslagh and Jemison, 1991). Post-acquisition integration represents a major organizational change process that requires extensive effort and resource dedication (Larsson and Finkelstein, 1999) and may divert managerial attention away from core activities (Yu et al., 2005). A challenge for acquiring firms is thus to deal with a demanding integration process, while maintaining focus on their ongoing activities (Puranam et al., 2003). However, an integration process rarely unfolds as a single initiative in an organization. Rather, organizations often carry out multiple and overlapping changes (Hafsi, 2001; Pettigrew et al., 2001). Managers in acquiring firms are thus faced with balancing integration of the focal acquisition and ongoing operations, while simultaneously managing other change processes.

Extant Mergers and Acquisitions ("M\&A") research has largely examined post-acquisition integration processes as isolated events (Laamanen and Keil, 2008). In this manner scholars have focused on managerial decisions and outcomes of the focal integration process without acknowledging the broader organizational context within which these decisions and outcomes unfold. This organizational context consists of strategic issues and change processes that, although exogenous to the focal acquisition, may significantly shape the integration process and its outcomes. We argue that to further our understanding of the dynamics and complexities of post-acquisition integration, we need to broaden the focus of inquiry beyond the specific integration process. Thus, in this study, we ask: 'how is the unfolding of the integration process shaped by other strategic initiatives and ongoing changes in the organizational context?'

In order to gain a rich understanding of how post acquisition integration may unfold, we gained access to a French multinational company (MNC-Metals) as it was acquiring a Norwegian firm (Beta-Mang). Shortly after the acquisition announcement, the companies faced a significant drop in demand due to the economic crisis of 2008. This presented managers with major 
challenges in carrying out the integration process, while managing the consequences of the drop in demand. Distressed firms face scarce resources, diminished managerial discretion and restrictive stakeholders (Trahms et al., 2013). As such, the case represented a particularly revealing opportunity to explore inductively how the unfolding integration process is shaped by other ongoing initiatives in the organization.

Our findings are twofold. First, we identified three ongoing processes in the firms: operations, crisis management, and post-acquisition integration processes. We found that organizational members' perceptions and actions, and ultimately integration outcomes, are intertwined across these processes. In this manner, the focal integration process does not unfold as a self-contained process, but rather as embedded within a set of co-evolving organizational processes. Second, we identified four mechanisms (coordination, cohesion, disconnection, alienation) that either facilitate or impede integration, thus shaping the unfolding of the integration process.

Our findings contribute to the understanding of post-acquisition integration dynamics. First, we theorize integration dynamics by recasting the post-acquisition integration process as embedded in a set of ongoing, simultaneous and co-evolving processes. Second, we conceptualize the micro tensions inherent in task and human integration processes that shape the unfolding of post-acquisition integration. Third, we uncover how the loci of causal ambiguity between integration decisions and outcomes may be exogenous to the integration process itself. Finally, we identify the contingencies for managerial agency in post-acquisition integration as dynamic and emergent, leading to a refined understanding of unintended integration outcomes.

\section{LITERATURE REVIEW}

Post-acquisition integration is a means to manage interdependencies and secure efficient and effective use of resources by making "changes in the functional activity arrangements, organizational structures and systems, and cultures of combining organizations" (Pablo, 1994: 
806). M\&A scholars have addressed the challenge managers face in defining the appropriate level of integration as the integration-autonomy dilemma (Zaheer et al., 2013). On the one hand, integration is required for knowledge and capability transfers and to achieve coordination benefits and synergies (Bresman et al., 1999; Haspeslagh and Jemison, 1991). On the other hand, there is a need to preserve the autonomy of the target, as integration may disrupt the task environment, and subsequently destroy the target's capabilities (Graebner, 2004; Puranam et al., 2003; 2006; Puranam et al., 2009).

Depending on the need for autonomy and the need for strategic interdependence, managers can choose different integration approaches to secure value creation. The target and the acquiring firms may blend into one new organization, the acquirer may assimilate the target, or the target may become a stand-alone after the acquisition (Angwin and Meadows, 2015). Scholars have suggested hybrid approaches to integration, allowing for linking of non-core activities, while preserving the strategic capabilities of the firm (Haspeslagh and Jemison, 1991, Schweizer, 2005).

Research has focused on the integration process as shaped by managers' decisions regarding mode and speed of integration, that ultimately influence acquisition outcomes (Haspeslagh and Jemison, 1991; Jemison and Sitkin, 1986; Pablo, 1994). Birkinshaw et al. (2000) contend that managers seek to limit the risks associated with integration by first attending to the preacquisition units' performance, before coordinating activities between the units. They distinguish between task integration and human integration. Task integration involves the transfer of capabilities and sharing of resources, while human integration is defined as the generation of satisfaction and the development of a shared identity among employees of both firms. Successful integration requires initial limited task integration, allowing firms to develop social relations, subsequently laying the foundations for later coordination. Noting the lack of clarity in the causal link between integration decisions and their performance outcomes, 
Cording et al. (2008) introduced the concept of "intermediate goals" that mediate the relationship between acquisition decisions and acquisition outcomes within the focal integration process. Extant research has thus searched for explanatory factors for M\&A outcomes by exploring the link between integration decisions and outcomes, largely ignoring the context the integration process is embedded in.

Organizations regularly undergo multiple and overlapping changes (Pettigrew et al. 2001). Subsequently, the integration process unfolds in a context of other ongoing organizational changes and strategic initiatives that are exogenous to the integration process itself. The organizational context is not just a stimulus environment, but a nested arrangement of structures and processes shaped by the subjective interpretations of actors (Pettigrew, 1992). The organizational context in which decision makers operate, determines what issues they give attention to, and their subsequent actions (Ocasio, 1997). Post-acquisition, managerial resources are strained as managers need to deal with business-as-usual and resource demanding integration activities. We know that lack of managerial attention to integration issues is detrimental to acquisition outcomes (Yu et al., 2005). However, our knowledge is limited of how strategic initiatives and organizational changes exogenous to post-acquisition integration, may strain managerial resources and thus shape integration decisions and managerial actions during post-acquisition integration. We argue that to further our knowledge of the dynamics of post-acquisition integration processes and the link between integration decisions and integration outcomes, it is necessary to go beyond the integration process itself, and examine it in its context.

\section{METHODS}

\section{Research method}


In July 2008, the first author met the newly appointed integration manager from MNC-Metals at a yearly meeting of a professional association. This person was sensitive to the difficulties that companies usually face during integration processes and was willing to launch a research project designed to examine the integration process over time. The original goal of the research project was to analyze the integration process within the organizations and to examine employees' perceptions during this major organizational change through a longitudinal, qualitative case study approach. The case study is the appropriate research technique for studying complex phenomena within their contexts (Yin, 1994). To understand the complexities of the post-acquisition integration process, it is necessary to let the integration process reveal itself in a temporal and contextual manner (Pettigrew, 1990). Qualitative methods offer rich information (Miles and Huberman, 1994), not accessible by cross sectional survey based methodologies and are well suited to access organizational members' accounts and interpretations (Maitlis, 2005). In this study, we adopted an interpretivist approach and analyzed the case from the perspective of those living it (Corley, 2015).

As we were planning our first data gathering in September 2008, a drop in demand suddenly and strongly, hit the case companies. Even though the case, as such, is a convenience case, it is also a revelatory case (Harrison and Rouse, 2015; Patton, 1990) as it provided us with an unexpected and unique opportunity to examine in real time how the consequences of an event, exogenous to the integration process itself, shapes managerial actions and ultimately integration activities.

\section{Research setting}

We examine the acquisition of Beta-Mang by MNC-Metals. MNC-Metals is a French Multinational operating in 20 countries over five continents. It is the second largest producer 
of high-grade manganese ore and manganese alloys, and the leading producer of refined manganese alloys worldwide. At the industry level, more than $90 \%$ of the total world production of manganese is used in the form of ferro-alloys, mainly in the steel industry (construction, automobile). Before the acquisition of Beta-Mang in 2008, MNC-Metals already had a Norwegian subsidiary: Alpha-Mang. Alpha-Mang consisted of two manganese plants acquired by MNC-Metals in 1999. Each plant had around 200 employees. Since 1999, MNC-Metals had invested considerably in the Norwegian plants. The central headquarters of MNC-Metals in Paris allowed Alpha-Mang substantial autonomy on operational issues. The top management team of Alpha-Mang consisted of Norwegian nationals, except for the CFO, who was French. Alpha-Mang and Beta-Mang had a long-standing, commercial relationship prior to the acquisition.

Beta-Mang was a Norwegian family-owned company founded in 1875. Beta-Mang consisted of a silico-manganese plant (200 employees) and a titanium and high purity iron plant (200 employees). Beta-Mang had a trading subsidiary for metallurgical product (67 employees) and shares in several power plants in Norway. In 2007, Beta-Mang recorded a turnover of $€ 931$ million.

Immediately after the acquisition, MNC-Metals divested the trading subsidiary and the power plants of Beta-Mang. The titanium plant was integrated into another branch of MNC-Metals. Our case is thus the integration of Beta-Mang silico-manganese plant, into the existing Norwegian operations of Alpha-Mang, implying the coordination of the three plants at the Norwegian subsidiary level.

\section{Data gathering}

Our case data consists of rich, longitudinal, primary data (in-depth interviews and informal observations and conversations) and secondary archival data (integration newsletters, 
integration plans and other internal documents). The archival data mostly addressed the financial structure of the deal and helped us to understand the timeline of events. These documents complemented our in-depth interviews and helped triangulate some of our findings.

We conducted 3 rounds of data collection in the headquarters of MNC-Metals and in the Norwegian plants of Alpha-Mang and Beta-Mang. The first consisted of 56 interviews, from May to July 2009. Through these interviews we gained insight into the research setting and built interactional expertise, which is needed to fully grasp context in a qualitative process study (Collins, 2004; Langley et al, 2013). At this point, the plants were directly impacted by the drop in demand thus allowing us to collect real-time data about managers' actions to cope with the crisis and employees' perceptions on these initiatives. From November 2009 to February 2010, production slowly returned to pre-crisis levels. During this period, we conducted our second round of data collection consisting of 49 interviews. Finally, from November 2010 to January 2011, we conducted our third round of data collection consisting of 46 interviews. At this point the production and the support functions (R\&D and HRM) of the three plants were coordinated at the Norwegian level. Furthermore, the Norwegian subsidiary began coordinating its activities with MNC-Metals'subsidiaries in Gabon and in the USA.

In order to ensure that multiple viewpoints were captured in our data, we interviewed people from different plants and at different levels of the organizations. Key informants were chosen on the basis that they had access to specific information relevant to the research enquiry. This included top management team, HR personnel, and employees with specific integration responsibilities.

\section{INSERT TABLE A.1 ABOUT HERE}

The interview guide consisted of open-ended questions in order to encourage informants to account for their experiences of the integration and the crisis. For instance, we asked informants to share their perceptions about how the integration process was managed; how the drop in 
demand was handled and how they were affected by the changes linked to the integration process or to the crisis management initiatives. Follow-up questions were used to get beneath general responses and to further explore key issues. As the informants shared their experiences, they were also encouraged to give their assessments and feelings towards the events and actions they described. We conducted the interviews in the native language of each respondent (either Norwegian or French). Interviews typically lasted between 45 and 90 minutes. We interviewed until saturation in each phase, that is, until each new interview added little new information (Charmaz, 2006). After each phase of data collection, we presented our findings to the top management of MNC-Metals in Paris. This feedback process constituted an opportunity to discuss and validate our findings.

\section{Data analysis}

All interviews were transcribed, yielding approximately 2,700 double spaced pages of transcripts. We read and re-read the transcripts, looking for recurring themes in the data (Van Maanen, 1998). We conducted an inductive and iterative analysis organized in four main phases. In the first phase, we extracted quotes that reflected the stories of the post-acquisition integration process (Langley et al., 2012). Dominant themes in our informants' accounts were their perceptions of events and activities unfolding related to the three distinct processes of crisis management, post-acquisition integration and ongoing operations. We gathered raw data into categories (Coffey and Atkinson, 1996) that encompassed operations management, crisis management, integration management. This prompted us to focus on how these processes were intertwined. We specifically paid attention to our informant's descriptions of the relationships between the processes, exemplified by claims such as: "it has been implemented faster because of the crisis" or "it was slowed down because of temporary lay-offs due to the crisis". Parallel to this first step of inductive coding of interviews, we carefully analyzed the content of archival data. For example, we juxtaposed quotes from our interview data related to expected and 
achieved synergies with descriptions of planned and achieved synergies in the integration newsletters. MNC-Metals and Beta-Mang had defined, in the pre-acquisition phase, the time (in months) needed to implement the main synergies (optimization of raw material supply, specialization of plants and coordination in purchase and logistics). We compared the schedule with actual progress to see whether the changes associated with each synergy were implemented faster or slower than planned.

In the second coding phase, we went back to the data and uncovered four mechanisms that underlie faster or slower achievement of synergies. We identified cohesion (i.e. informants' descriptions of the crisis as a common enemy to fight against), alienation (i.e. informants' descriptions of lack of interactions between the plants), coordination (i.e. informants' descriptions of increased synergy hunt and implementation of coordination structures) and disconnection (i.e. informants' descriptions of perception of competition for resources) as key categories.

Third, we reverted to the literature on post-acquisition integration to make sense of our preliminary findings on the four mechanisms. In line with Birkinshaw et al., (2000), we identified coordination and disconnection as components of task integration and cohesion and alienation as components of human integration.

Fourth, following axial coding (Strauss and Corbin, 1998), we searched for relationships between the mechanisms identified in the previous coding phases. As such, we abstracted dynamic tensions between coordination and disconnection and dynamic tensions between alienation and cohesion as presented in our emergent model in the findings section.

\section{FINDINGS}

In the following section, we present our findings in a narrative manner with quotes to illustrate our interpretations. Following Langley's recommendations (1999) on temporal bracketing, we 
first present our findings as a description of events that reflects the reality of the integration process. We have identified three phases: (1) pre-acquisition: acquisition announcement and integration planning, (2) early post-acquisition: drop in demand and crisis management and (3) later post-acquisition: back to normal operations and finalizing integration. From this longitudinal and narrative analysis, we then present two models that emerged from our data analysis. First, our data show how the post-acquisition integration process co-evolves with other ongoing and overlapping processes in the organization. We identified three main ongoing processes: 1) integration, 2) crisis management and 3) operations. We observed that organizational members' perceptions, actions and outcomes, related to each process, were intertwined. Second, we found a set of mechanisms (cohesion, alienation, coordination and disconnection) that arise from this set of co-evolving processes and that both facilitated and impeded task and human integration.

\section{Pre-acquisition: Acquisition announcement and integration planning}

MNC-Metals announced the friendly acquisition of Beta-Mang in April 2008. The overall goal of the acquisition was to reinforce MNC-Metals' position as one of the world's leading producers of manganese alloy. MNC-Metals estimated an increase in the production of manganese alloy from the acquisition of approximately $20 \%$. Top managers of both firms expected minimum annual operational synergies of $€ 10$ million to $€ 15$ million from cost saving, revenue enhancement and knowledge sharing. These would be achieved by securing BetaMang's supplies of low-carbon manganese, increasing production capacity, improving value chain coordination and gaining economies of scale in purchasing and logistics. To achieve these synergies, the two Alpha-Mang plants' furnaces would now specialize in low carbon manganese, while the Beta-Mang plant would specialize in silico-manganese. By only focusing 
on only one product per furnace, maintenance costs would be reduced and production capacity and efficiency increased. No reduction in workforce was planned.

Synergies were also expected from exchanges of knowledge and best practices in operation management, health and safety at work. Indeed, the Beta-Mang plant had outstanding records for health and safety at work (few incidents were recorded the five years prior to the acquisition). MNC-Metals intended to transfer Beta-Mang's health and safety procedures to Alpha-Mang plants to reduce the frequency and severity rates of incidents in its plants. The integration plan included the implementation of all operational synergies within a year postacquisition. To facilitate control, IT systems coordination was to be implemented in approximately nine months post-acquisition.

In June 2008, MNC-Metals acquired 56\% of Beta-Mang shares. Beta-Mang had had two main owners with $93 \%$ of the total shares (respectively 56 and 37\%). The deal stated that the remaining $37 \%$ of shares, belonging to the other main owner, were due to be acquired in December 2008. In June 2008, management established 13 integration workshops involving 50 employees and managers from both companies. These workshops were tasked to map processes and practices and evaluate synergies and cost savings opportunities in all functions. The 13 workshops included Logistic, Production reallocation, R\&D, Benchmarking, Management team, Energy, Accounting, Human Resources Management, Health and Safety, Purchasing, IT, Legal Structure and Commercial. Each integration workshop involved 3 to 11 persons. The integration manager, the top management team and two employees of the three plants were in charge of following the progression of the 13 integration workshops.

In this early phase employees from both side of the deal were positive towards the opportunities presented by the acquisition:

\footnotetext{
"The merger plan was met with positive minds (....). When the integration process began, we found it very exciting to explore how another organization is working to reach similar goals" (Employee, Alpha-Mang).
} 
Employees from Alpha-Mang and Beta-Mang were acquainted through pre-existing labor union affiliation and commercial relationships. Alpha-Mang informants explained that MNCMetals had been a "good owner" to the Norwegian plants. They appreciated the management style of MNC-Metals and acknowledged the investments MNC-Metals had made in the plants. When interacting with their new colleagues of Beta-Mang, Alpha-Mang employees communicated their positive perceptions of MNC-Metals and the integration process. BetaMang employees described how the workshops were key arenas for developing collaborative relationships and sharing knowledge between the firms. They indicated that they felt that their voice was heard and their opinion valued:
"I'm very satisfied with this first phase [workshops]. Alpha-Mang has included us in all parts of the work. We have had the possibility to give comments and to work as a team from day one. (Employee, Beta-Mang).

Employees, both from Alpha-Mang and Beta-Mang, indicated that they were motivated to work on the development of integration initiatives through the workshops:

It has been a lot of work but the results and the synergies, which are pointed out, give me a great motivation" (Employee, Beta-Mang).

Top managers disclosed that a key concern in the integration process was respecting the organizational cultures and the balance of power between Alpha-Mang and Beta-Mang. Top management's willingness to respect the partner was diffused into all hierarchical level and facilitated the emergence of a collaborative work environment. This was echoed in the accounts of the participants of the workshops:

\footnotetext{
"The atmosphere in the workshop is positive. In all groups, we have focused on opening up, sharing knowledge and looking for synergies, which could give savings. Also, we have learned to know each other and work together. This will be important in the time to come" (Manager, Beta-Mang).
}

In the summer 2008, the integration process was proceeding smoothly. Employees from both sides of the deal were positive about the acquisition. It was perceived as a smart move and organizational members were satisfied with their commitment in integration workshops. 


\title{
Early post-acquisition: Drop in demand and crisis management
}

In the fall of 2008, a collapse of steel consumption led to a dramatic drop in demand for the firms' products:

\begin{abstract}
"The market had turned around: steel production in Europe, in North America and in China has dramatically dropped as a consequence of a brutal collapse of the steel consumption (...). We have gone almost overnight from a seller's market to a buyer's market. Orders are hard to find, prices are decreasing (...)" (Manager, Alpha-Mang).
\end{abstract}

The drop in demand led to the deterioration of MNC-Metals' share price. Subsequently, the conditions of the exchange of shares with the second shareholder could no longer be met. He thus postponed the sale of his shares (37\%). This delay in full ownership impeded MNCMetals' ability to implement the specialization of plants, thus slowing down the original integration plan. The delay in full ownership created uncertainty among employees about the future integration. Some employees voiced doubts about MNC-Metals' full ownership of BetaMang, and thus their ability to implement the integration plan and to realize the synergies.

The drop in demand implied that managers, already burdened by integration activities, also needed to address the crisis. The integration team and the managers were suddenly tasked with the responsibilities for reducing costs and gaining gain control over inventories to avoid overcapacity.

During the winter of 2009 , the top management team decided to temporarily shut down production and temporarily lay-off employees to cope with over-capacity. This resulted in limited activity in the plants and minimal interaction between employees:

\footnotetext{
"Now we have temporary lay-offs, but of course, when we are in full operation again, and when we are allowed to travel again, then we can get access to how they do things, and there are synergies, specifically in $R \& D$ and operations management." (Employee, Alpha-Mang).
}

In addition to temporary lay-offs, managers implemented additional cost reduction actions that further reduced interactions between plants. Planned travels and visits between the plants were 
cancelled and restrictions were made on future travel for line-managers and lower level employees. Top-level management was exempt from restrictions on travel, and the union representatives from the plants still interacted throughout their union networks. As one employee describes:

"There are cost-cutting initiatives, so there is not a lot of travelling. It is not that easy to learn from one another when we can't come and see what the others are doing. There is no contact across the plants." (Employee, Beta-Mang).

Securing low-cost access to raw materials for Beta-Mang production plants was a key driver behind the deal. This became even more important as the crisis hit the plants. To address the crisis, efforts were made to facilitate the circulation of raw materials from Alpha-Mang to BetaMang and to increase the coordination between the different steps in the value chain. AlphaMang's IT systems and reporting systems were also implemented in Beta-Mang faster than initially planned, as the need to monitor costs increased due to the crisis. The emergent need for cost-control also triggered the establishment of coordination structures that were not initially forecasted in the integration plan. A task force was thus created and worked as an efficient coordination structure:

"During the summer 2009, to face the crisis, we created a task force to manage inventories. The team made of Norwegians and French from the sales and the production departments met every 10 days. (Manager, Alpha-Mang).

Organizing the temporary lay-off was a task for general managers and HR managers. HR managers were involved in securing compensation for employees and organizing the schedule for the operators and this took focus away from integration issues. Management resources were also involved in extensive communication with the organization to mitigate employee unrest and worries about lay-offs.

Management attention and resources were already strained from integration efforts, and, dealing with the crisis further spread attention and resources more thinly still. The increased 
focus on financial reporting and coordinating cost initiatives was time consuming for top managers, line managers and controlling function. In addition, these initiatives were described by the plant managers as having shifted management attention from coordination and building ties between the plants, to managing issues within each plant.
"We have been allowed to loosen the tie to the other plants to focus on this plant. We are running at a lower capacity, we have a different culture, and there will be lower production before there is an up-turn, so I think it is right to let our plant run its own, independent developmental process and self-cultivate" (Alpha-Mang manager).

The delay in full ownership and the crisis management initiatives created some uncertainties about the acquisition amongst employees and their initial positive perceptions of the merits of the acquisition waned. As the drop in demand hit the plants, employees' perceptions about the cause of the crisis became blurred. Employees tended to blame the acquisition for the economic troubles and the shutdown of the plants. As described by these Alpha-Mang managers:

\footnotetext{
"We had to manage the risk of confusion between crisis related issues and integration issues in [Beta-Mang] employees' mind. We had to communicate a lot to clarify the situation" (Alpha-Mang Sales VP).

"The main challenge now for us, as leaders, is to communicate and make people understand the crisis." (Alpha-Mang manager).
}

In addition to the confusion around the cause of the economic problems, employees also claimed that Beta-Mang management would have handled the crisis better than Alpha-Mang. For example, when addressing the shutdown of his plant, one Beta-Mang employee described: "We at Beta-Mang, we would have done differently (regarding plant shutdown)". One manager described how the fear and discontent about the crisis "spilled over" into perceptions about the acquisition:
"When everything is $O K$, people are happy with the merger with Alpha-Mang. When there is a negative situation, it's Alpha-Mang's fault. Employees in my plant think that the crisis would have been softer without Alpha-Mang" (Plant Manager, Beta-Mang).

In parallel, our informants described their perceptions of "fighting against a common enemy" and "being in the same boat" as all the plants were exposed to the drop in demand and shared 
the same challenges in dealing with this crisis. Beta-Mang and Alpha-Mang employees and managers described that they needed to work together in a cohesive way to cooperate and face the crisis.

"When the crisis hit us, we all stuck together. Nobody tried to save himself at the expense of others. We were not pulling dirty tricks on each other. People were trying to solve the problems; they were helping each other whatever their plants or their nationalities. I would say that we were solidary in adversity. I wonder whether this will last once the crisis is over" (CFO Alpha-Mang)

Our informants also described how the crisis brought the Norwegian plants together as they were lobbying for resources in competition with all production units worldwide in a strained MNC. Informants described the importance of making the Norwegian plants as an entity geared towards competing with low-cost resources in the rest of the world:

\footnotetext{
"The challenge is to make MNC-Metals happy with us. They are global, and can get their ore processed in other places (...). Our challenge is to make sure the Norwegian plants are prioritized in the future." (Beta-Mang employee)
}

Employees in the acquired plant voiced their fear of losing bargaining power at the plant level. As one of many plants in MNC-Metals, they felt alienated and removed from decisions made at the headquarters in Paris. Pre-acquisition they had been close to decision making processes and without other plants competing for resources. As the decision to temporarily shut down production was made, the acquired plant employees were concerned about the future of their plants, as MNC-Metals had many other plants they could use.

\footnotetext{
"Now people here feel the competition. We are three of sixteen furnaces in Norway, and we have to do what we can do to make sure that our furnaces are up and running. We cannot produce to store anymore. We are publicly listed and everything needs to be reported. We are challenged on the numbers - what last month's numbers were. (...) there is now competition between the plants about who gets to produce." (Beta-Mang employee)

"If you compare us with the other plants (in Norway) we are at the top. (...) We have to show them that we are good, so that we get the necessary investments to run the plant the way it was run before. "(Beta-Mang employee)
}

In the same vein, the existing Alpha-Mang plants in Norway were concerned about internal competition from the newly acquired plant. The pre-acquisition relationship between the two 
Alpha-Mang plants in Norway had been very competitive. The crisis and the acquisition increased competition for resources from the French headquarters of MNC-Metals. In one of the Alpha-Mang plants their fear was grounded in their perception of the other plant was closer to the top management of the Norwegian subsidiary:

\footnotetext{
"We are further away from the corporate [Norwegian] headquarter, and they are prioritized (...) that is where the management team is, they are preferred" (Employee, Alpha-Mang).
}

Beyond fears and perceptions, facts and figures about cut backs on investments from MNC-

Metals headquarters were an objective measure of an increased competition between plants:

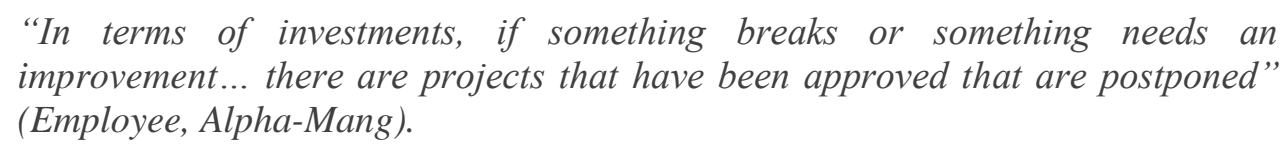

\section{Later post-acquisition: Back to normal operations and finalizing integration}

After twelve months of uncertainty, demand increased in September 2009. The plants resumed to normal production levels, temporary lay-offs ceased and integration activities were continued. In the spring of 2010, the planned integration activities had all been carried out.

Our informants described how the crisis had pushed some aspects of the integration process forward unintentionally, as crisis management efforts were conducive to hunting for new ideas and solutions:

"The crisis literally boosted the hunt for new ideas and solutions. Some decisions taken to manage the crisis, even if they had no direct link with the synergies, had a positive effect on the integration process. This effervescence of solution was very good for the success of the integration" (Manager, Alpha-Mang). 
We observed that of the five integration objectives defined by top managers in the pre-deal phase to create value from the acquisition, some were implemented faster and some were delayed. On the one hand, IT Systems integration, optimization of raw material supply and coordination in purchasing and logistics were carried out sooner than planned as a result of the crisis management activities. Managers described how the crisis management initiatives pushed forward the integration process:

\begin{abstract}
"Before the merger, we had defined a schedule for the implementation of our cost control and cash management software in the plants acquired. Because of the crisis, we had to accelerate its implementation; consequently, we now have efficient reporting six months in advance compared to what was initially planned" (Manager, Alpha-Mang).
\end{abstract}

On the other hand, the crisis management initiatives to control costs and avoid over-capacity together with lack of full ownership had led to a delay in plant specialization and knowledge transfer. Indeed, employees could not meet up to share best practices because of temporary layoffs and cut back in travel expenses, thus slowing down these integration activities.

Tables A.2 and A.3 detail the integration objectives that were reached faster or slower as a result of crisis management initiatives.

\title{
INSERT TABLES A.2 AND A.3 HERE
}

In addition to accelerating or slowing down the implementation of synergies, we also observed that management structures put in place during the crisis became permanent structures after the plants resumed normal production levels. This was because they were conducive to integration at the Norwegian level and also functioned as wider integration mechanisms within MNCMetals. As a manager explains:

"This task force was supposed to be a transient structure of adjustment during the crisis. But as it worked out very well, we decide to perennialize this mode of management" (Manager, MNC-Metals).

"We created task forces to manage inventories. We involved people from management control, purchasing, sales and production. These structures were created spontaneously to face the crisis and they actually last because they work. 
They help strengthening the ties between Paris and Norway and also between the

different plants" (CFO Alpha-Mang).

\section{Post-acquisition integration as embedded in the context of co-evolving}

\section{processes}

We identified three simultaneously unfolding processes in our case; post-acquisition integration, crisis management and ongoing operations of the plants. Whereas we identified these processes as conceptually distinct and discernible, our findings also show how they were nested and intertwined. Organizational members' perceptions and actions, and the outcomes of post-acquisition integration were shaped by their perceptions and actions, and the outcomes of the processes of crisis management and ongoing operations. Thus, the integration outcomes we observed could not be attributed solely to integration decisions and initiatives.

First, we observed that crisis management initiatives shifted employees' perceptions about the acquisition. Initially employees were cooperative and optimistic about the future coordination of the value chain. With the event of the crisis they developed negative attitudes towards the acquisition, as they confused organizational crisis issues with post-acquisition integration related issues. Employees' positive perceptions about the merits of the acquisition vanished as they perceived that crisis management initiatives to avoid over-capacity could have been implemented differently. In this manner, perceptions of the crisis and the acquisition were muddled.

Second, the actions aimed at managing the drop in demand had unintended consequences for the unfolding integration process. For example, shutdown in production and cost-cutting initiatives limited interactions between employees from the three plants and reduced knowledge transfer that was a key part of the original integration plan. Also, we observed that the coordination structure implemented to cope with over-capacity was then subsequently sustained 
as an integration structure to facilitate coordination between the Norwegian subsidiary and headquarters. In this manner, actions and outcomes of the crisis, ongoing operations and acquisition were muddled.

Third, we observed the feed-back loop, wherein the outcomes of the various processes contributed to the perceptions of the acquisition or the crisis. For example, purchasing and logistics were coordinated across the plants six months ahead of schedule as part of the crisis management initiatives. This, in turn, shaped organizational members' perceptions of the acquisition.

Our findings show that post-acquisition integration does not unfold as a self-contained process but rather that it is embedded within a set of co-evolving organizational processes. Each dimension of a process (perceptions, actions, outcomes), is nested and mutually constitutive with those of the other processes, making the various processes intertwined.

\section{INSERT FIGURE A.4. ABOUT HERE}

\section{The dynamic tensions of post-acquisition-integration}

We identified four mechanisms at work in the integration process that arise from the set of coevolving processes presented above: coordination, cohesion, disconnection, and alienation.

First, coordination and cohesion facilitated integration. Crisis management initiatives boosted the hunt for solutions to face the drop in demand. For example, task-force structures that enhanced coordination of activities between the plants were established thus improving task integration. Furthermore, organizational members 'perceptions of the crisis as a common enemy to fight against, fostered cohesion between the three plants, thus enhancing human integration.

Second, disconnection and alienation impeded integration. Competition between plants and lack of knowledge sharing generated disconnection between employees and impeded task 
integration. Organizational members perceived themselves as not belonging to MNC-Metals and felt excluded from decision-making processes in MNC-Metals, leading to their alienation from the acquiring firm. Such alienation impeded human integration.

Overall, our findings show that coordination and cohesion are mechanisms that facilitate integration while disconnection and alienation are mechanisms that impede integration. Our emergent model conceptualizes the tension between coordination and disconnection and the tension between cohesion and alienation as tensions between facilitators and impediments of integration processes. We thus argue that integration processes unfold in a dialectic and dynamic manner with forces simultaneously impeding and facilitating integration.

\section{INSERT FIGURE A.5. ABOUT HERE}

\section{DISCUSSION}

We explored how post-acquisition integration processes are shaped by strategic initiatives and ongoing changes in the organization exogenous to the integration process. We found that organizational members are faced with a host of issues and initiatives to make sense of, and act upon. This resulted in a complexity of intertwined perceptions, actions and outcomes. We thus identified post-acquisition integration as embedded in the context of co-evolving processes. From these co-evolving processes, we found four mechanisms at work. Coordination and cohesion operate as integration facilitators while disconnection and alienation operate integration impediments. Our model conceptualizes the tensions between integration facilitators and integration impediments that shape the unfolding of the integration process. We thus recast the integration process as embedded in a set of co-evolving processes, wherein the 
conceptualized tensions between integration facilitators and integration impediments lead to its dialectic, emergent and dynamic unfolding.

\section{Contributions and Implications}

Recent calls have been made to explore the dynamics of post-acquisition integration (Graebner et al., 2017). Our findings contribute to the existing literature on post-M\&A integration by exposing the complexities of these dynamics. First, we recast the post-acquisition integration process as embedded in a set of ongoing, simultaneous and co-evolving processes. Our findings identify the loci of the integration dynamics in processes exogenous to the integration process itself. Doing so, we show how the discrepancy between integration decision and integration outcomes can reside in the tensions we observed. Indeed, these tensions shape the integration process, diverting its intended linear trajectory.

Second, we extend Birkinshaw et al.'s (2000) work by identifying and conceptualizing the micro tensions inherent in task and human integration. We highlight the dynamic tensions of coordination/disconnection and cohesion/alienation that impede and facilitate both subprocesses of human and task integration and lead to the dialectic unfolding of integration.

Third, adopting an embedded perspective, we contribute to the understanding of acquisition outcomes by pinpointing important "unidentified variables" (King et al., 2004) and “intermediate variables" (Cording et al., 2008). We challenge the conception of the integration process as self-contained by identifying "intermediate variables" emerging from the set of coevolving processes. Thus the loci of causal ambiguity between integration decisions and outcomes, may be exogenous to the integration process itself. The extant M\&A literature has been rather silent as to the role of the organizational context in which post-acquisition integration is situated. Our findings conceptualize the mechanisms through which organizational context matters and thus challenge the traditional view of the boundaries of the 
integration process. Our findings imply the need to adopt an embedded perspective on M\&As and address post-acquisition integration as unfolding in a context of co-evolving processes.

Finally, our study exposes the dynamic, emergent and practice based aspects of M\&A integration that lead to the uncertainty commonly observed in post-acquisition integration (Teerikangas, 2012). Acquisition scholars have adopted a contingent approach that breaks with the original rational and intended view of post-acquisition integration (Cartwright and Cooper, 1993; Monin et al., 2013; Vaara, 2003). From extant research both on acquisitions and on strategic change, we know that managerial attention (Ocasio, 2011), managerial actions (Colman and Lunnan, 2011; Graebner 2004), and managerial sense-making (Balogun and Johnson 2005) shape how strategic intent translates into intended and unintended outcomes. Our findings build on this literature and identify the manner in which perceptions, actions and outcomes unfold and interact post-acquisition. We thus theorize the contingencies and consequences of integration outcomes, by identifying the mechanisms through which integration initiatives were facilitated or impeded.

\section{Managerial implications}

Previous studies have emphasized the need for communication to cope with employees' doubts and uncertainties post-acquisition (Angwin et al., 2016; Schweiger and Denisi, 1991). Our findings indicate the need for managers to take other strategic initiatives and ongoing processes in the organization into consideration in this communication. The M\&A integration process should not be addressed as an isolated change effort, but rather as embedded in the organizational context with other confounding issues. It is important to gauge employees' perceptions of all changes and develop sensitive and targeted communication. Overall, in an M\&A, managers should communicate clearly, proactively and interactively (Angwin et al., 2016) to enable organizational members to distinguish the decisions taken as a consequence of 
the integration and the decisions taken as a consequence of other processes exogenous to the integration process.

Our findings suggest that managers should adopt a less myopic view when evaluating the progress and efficiency of post-acquisition integration. Adopting an embedded perspective, managers can embrace the multiple objectives and the complexities of intertwined and coevolving process. For instance, they could assess the capacity of their integration managers and teams (Trichterborn et al., 2016) to adapt and redefine integration initiatives in a changing integration context. Recasting the integration process as an embedded process implies the need to adopt a broader, more contextualized view to evaluate post-acquisition integration efficiency.

\section{Boundary conditions and future directions}

Our work is not without limitations and each of these limitations opens an avenue for future research. First, our case focuses on an acquisition implementation within one subsidiary of an MNC. The integration process is thus limited to one institutional context and does not encompass issues of national cultural differences and geographical distance. Future research could replicate our work on integration processes involving cross-border units to study how the integration process is embedded in a larger set of co-evolving processes at the level of the MNC.

Second, in our case the acquiring firm needed to mitigate the consequences of a drop in demand while carrying out the integration process. The economic crisis significantly reduced the amount of organizational slack available and forced managers to focused on cost reducing activities and short-term profitability. Integration initiatives with less certain and immediate performance improvement effects were inhibited. If the acquiring firm was facing a change that increased organizational slack, this could reduce the urgency for cost reduction actions and increase focus on activities, such as knowledge exchange, that might lead to longer-term performance improvement. Other events and processes may affect merging organizations, and 
facilitate or impede integration. For instance, a sudden increase in demand, regulatory changes, stock market booms, political shocks, scandals and corruption may all shape the integration process. In the case of serial acquirers, there are continuous and overlapping integration or restructuring processes, both likely to influence the focal integration process. Future researches could replicate our study in other contexts to continue deepening our understanding of how events and processes, exogenous to the integration process itself, affect merging organizations. Third, as our case study illustrates, although post-acquisition integration processes are major events in an organization, they may be embedded in a variety of ongoing organizational processes and events as important as an integration process. The event of a major crisis may shape the integration process in a different manner than a more minor event. Future research could examine a variety of events with various significances and impacts to further analyze their impeding and facilitating effects on the integration process.

Overall, we conclude that multi-vocal influences are likely on the focal integration process, and applying an embedded perspective is valuable for understanding how the integration process unfolds and how integration decisions may differ from integration outcomes. 


\section{REFERENCES}

Angwin, D. N., Meadows, M., 2015. New integration strategies for post-acquisition management. Long Range Planning, 15, 235-251.

Angwin, D. N., Mellahi, K., Gomes, E., Peters, E. 2016. How communication approaches impact mergers and acquisitions outcomes, International Journal of Human Resource Management, 27, 2370-2397.

Balogun, J., \& Johnson, G. (2005). From Intended Strategies to Unintended Outcomes: The Impact of Change Recipient Sensemaking. Organization Studies, 26(11), 1573-1601.

Birkinshaw, J., Bresman, H., Hakanson, L., 2000. Managing the post-acquisition integration process: How the human integration and task integration processes interact to foster value creation. Journal of Management Studies, 37, 395-425.

Bresman, H., Birkinshaw, J., \& Nobel, R. 1999. Knowledge transfer in international acquisitions. Journal of International Business Studies, 41(1): 5-20.

Cartwright, S., Cooper, C. L., 1993. The psychological impact of merger and acquisition on the individual: a study of building society managers. Human Relations, 46, 327-347.

Charmaz, K., 2006. Constructing grounded theory: A practical guide through qualitative analysis. SAGE, London, UK.

Coffey, A., Atkinson, P., 1996. Making Sense of Qualitative Data: Complementary Research Strategies. Sage.

Collins, H., 2004. Interactional expertise as a third kind of knowledge. Phenomenology and the Cognitive Sciences, 3, 125-143.

Colman, H. L. \& Lunnan, R. 2011. Organizational Identification and Serendipitous Value Creation in Post-Acquisition Integration. Journal of Management, 37, 839-860.

Cording, M., Christmann, P., King, D. R., 2008. Reducing Causal Ambiguity In Acquisition

Integration: Intermediate Goals As Mediators of Integration Decisions and Acquisition Performance. Academy of Management Journal, 51, 744-767.

Corley, K.G. 2015. A commentary on "what grounded theory is..." Engaging a phenomenon from the perspective of those living it. Organizational Research Methods, 18, 600-605.

Graebner, M. E., 2004. Momentum and serendipity: how acquired leaders create value in the integration of technology firms. Strategic Management Journal, 25, 751-777.

Graebner, M. E., Heimeriks, K. H., Nguyen Huy, Q., \& Vaara, E. 2017. The process of postmerger integration: a review and agenda for future research. Academy of Management Annals, 11(1): 1-32.

Hafsi, T. 2001. Fundamental Dynamics in Complex Organizational Change: A Longitudinal Inquiry into Hydro-Québec's Management. Long Range Planning, 34(5), 557-583.

Harrison, S. H., Rouse, E. D., 2015. An inductive study of feedback interactions over the course of creative projects. Academy of Management Journal, 58, 375-404.

Haspeslagh, P. C., Jemison, D. B., 1991. Managing Acquisitions. Creating Value through Corporate Renewal. The Free Press, New York. 
Jemison, D. B., Sitkin, S., 1986. Corporate acquisitions: a process perspective. Academy of Management Review, 11, 145-163.

King, D. R., Dalton, E.R., Daily, C. M, Covin, J.G., 2004. Meta-analyses of post-acquisition performance: indiciations of unidentified moderators. Strategic Management Journal, 25, 187 -200 .

Laamanen, T., \& Keil, T. 2008. Performance of serial acquirers: toward an acquisition program perspective. Strategic Management Journal, 29(6): 663-672.

Langley, A. 1999. Strategies for theorizing from process data. Academy of Management Review, 24(4): 691-710.

Langley, A., Golden-Biddle, K., Reay, T., Denis, J.-L., Hébert, Y., Lamothe, L., Gervais, J., 2012. Identity Struggles in Merging Organizations: Renegotiating the Sameness-Difference Dialectic. The Journal of Applied Behavioral Science, 48, 135-167.

Langley, A. N. N., Smallman, C., Tsoukas, H., Van De Ven, A. H., 2013. Process studies of change in organization and management: unveiling temporality, activity, and flow. Academy of Management Journal, 56, 1-13.

Larsson, R., Finkelstein, S., 1999. Integrating strategic, organizational and human resources perspectives on mergers and acquisitions: a case survey of synergy realization. Organization Science, 10, 1-26.

Maitlis, S., 2005. The social processes of organizational sensemaking. Academy of Management Journal. 48, 21-49.

Miles, M. B., Huberman, A. M., 1994. Qualitative data analysis: An expanded sourcebook. Sage.

Monin, P., Noorderhaven, N., Vaara, E., Kroon, D., 2013. Giving sense to and making sense of justice in potsmerger integration. Academy of Management Journal, 56, 256-284.

Ocasio, W. (2011) Attention to attention, Organization Science, 22 (5), 1286-1296.

Ocasio, W. (1997) Towards an attention-based view of the firm, Strategic Management Journal, $18,187-207$.

Pablo, A., 1994. Determinants of acquisition integration level: a decision making perspective. Academy of Management Journal, 37, 803-836.

Patton, M. Q., 1990. Qualitative Evaluation and Research Methods (2nd ed.). Sage, Newbury Park, CA.

Pettigrew, A. M. 1990. Longitudinal Field Research on Change: Theory and Practice. Organization Science, 1(3): 267-292.

Pettigrew, A. M., 1992. The character and significance of strategy process research. Strategic Management Journal, 13, 5-16.

Pettigrew, A. M., Woodman, R. W., \& Cameron, K. S. 2001. Studying organizational change and development: Challenges for future research. Academy of Management Journal, 44(4), 697-713.

Puranam, P., Singh, H., \& Zollo, M. 2003. A Bird in the Hand or Two in the Bush?: Integration Trade-offs in Technology-grafting Acquisitions. European Management Journal, 21(2), 179. 
Puranam, P., Singh, H., \& Zollo, M. 2006. Organizing for innovation:managing the coordination-autonomy dilemma in technology acquisitions. Academy of Management Journal, 49(2), 263-280.

Puranam, P., Singh, H., \& Chaudhuri, S. 2009. Integrating Acquired Capabilities: When Structural Integration Is (Un)necessary. Organization Science, 20(2): 313-328.

Schweiger, D. M., Denisi, A., 1991. Communication with employees following a merger: a longitudinal field experiment. Academy of Management Journal, 34, 110-135.

Schweizer, L. 2005. Organizational integration of acquired biotechnology companies into pharmaceutical companies: The need for a hybird approach. Academy of Management Journal, 48(6): 1051-1074.

Strauss, A. L., Corbin, J., 1998. Basics of Qualitative Research (2nd ed.). Sage, Thousand Oaks, CA.

Teerikangas, S., 2012. Dynamics of acquired firm pre-acquisition employee reactions. Journal of Management, 38, 599-639.

Trahms, C. A., Ndofor, H. A., \& Sirmon, D. G. 2013. Organizational Decline and Turnaround: A Review and Agenda for Future Research. Journal of Management, 39(5), 1277-1307.

Trichterborn, A., Zu Knyphausen-Aufseß, D., \& Schweizer, L. 2016. How to improve acquisition performance: The role of a dedicated M\&A function, M\&A learning process, and M\&A capability. Strategic Management Journal, 37(4), 763-773.

Vaara, E., 2003. Post-acquisition Integration as Sensemaking: Glimpses of Ambiguity, Confusion, Hypocrisy, and Politicization. Journal of Management Studies, 40, 859-894.

Van Maanen, J., 1998. Qualitative studies of organizations. Sage.

Yin, R., 1994. Case study research - Design and methods (2nd ed.). Sage, CA.

Yu, J., Engleman, R.M.,Van de Ven, A. H., 2005. The Integration Journey: An Attention-Based View of the Merger and Acquisition Integration Process. Organization Studies. 25, 1501-1528

Zaheer, A., Castañer, X., Souder, D., 2013. Synergy Sources, Target Autonomy, and Integration in Acquisitions. Journal of Management, 39, 604-632. 


\section{APPENDIX A}

Table A.1. Breakdown of Interviews $(n=151)$ by Company, Hierarchical Level, and

\section{Period}

\begin{tabular}{ccccc}
$\begin{array}{c}\text { Company / Hierarchical } \\
\text { Level }\end{array}$ & $\begin{array}{c}\text { Round 1 } \\
\text { Spring-Summer } \\
2009\end{array}$ & $\begin{array}{c}\text { Round 2 } \\
\text { Fall 2009 to Winter } \\
2010\end{array}$ & $\begin{array}{c}\text { Round 3 } \\
\text { Fall 2010 to Winter } \\
2011\end{array}$ & Total \\
\hline MNC-Metals managers & 7 & 6 & 7 & 20 \\
Alpha-Mang managers & 8 & 5 & 7 & 20 \\
Alpha-Mang employees & 15 & 15 & 13 & 43 \\
Beta-Mang managers & 9 & 10 & 9 & 28 \\
Beta-Mang employees & 17 & 13 & 10 & 40 \\
\hline Total & 56 & 49 & 46 & 151
\end{tabular}


Table A.2. Integration areas that sped up: Comparison of intended and actual integration implementation

\begin{tabular}{|l|c|c|l|}
\hline \multicolumn{1}{|c|}{$\begin{array}{c}\text { Integration } \\
\text { Objectives }\end{array}$} & $\begin{array}{c}\text { Intended } \\
\text { integration } \\
\text { timeline }\end{array}$ & $\begin{array}{c}\text { Actual } \\
\text { integration } \\
\text { timeline }\end{array}$ & \\
\hline $\begin{array}{l}\text { IT Systems } \\
\text { integration }\end{array}$ & $\mathrm{T}_{0}=>\mathrm{T}_{9}$ & $\mathrm{~T}_{0}=>\mathrm{T}_{3}$ & $\begin{array}{l}\text { Implementation of IT systems in Beta- } \\
\text { Mang plants was accelerated to better } \\
\text { control costs in a crisis context. }\end{array}$ \\
\hline $\begin{array}{l}\text { Optimization of } \\
\text { raw material } \\
\text { supply }\end{array}$ & $\mathrm{T}_{0}=>\mathrm{T}_{12}$ & $\mathrm{~T}_{0}=>\mathrm{T}_{3}$ & $\begin{array}{l}\text { Optimization of raw material supply was } \\
\text { accelerated to secure low-cost access to } \\
\text { raw material and subsequently reduce } \\
\text { costs in a crisis context. }\end{array}$ \\
\hline $\begin{array}{l}\text { Coordination in } \\
\text { purchasing and } \\
\text { logistics }\end{array}$ & $\mathrm{T}_{0}=>\mathrm{T}_{12}$ & $\mathrm{~T}_{0}=>\mathrm{T}_{6}$ & $\begin{array}{l}\text { Coordination in purchasing and logistics } \\
\text { was accelerated to reduce costs in a crisis } \\
\text { context. }\end{array}$ \\
\hline
\end{tabular}

\footnotetext{
${ }^{1}$ Duration is expressed in months elapsed since the start of the acquisition in June $2008\left(\mathrm{~T}_{0}\right)$
} 
Table A.3. Integration areas that slowed down: Comparison of intended and actual integration implementation

\begin{tabular}{|l|c|c|l|}
\hline \multicolumn{1}{|c|}{$\begin{array}{c}\text { Integration } \\
\text { Objectives }\end{array}$} & $\begin{array}{c}\text { Intended } \\
\text { integration } \\
\text { timeline }\end{array}$ & $\begin{array}{c}\text { Actual } \\
\text { integration } \\
\text { timeline }\end{array}$ & \\
\hline Plant specialization & $\mathrm{T}_{0}=>\mathrm{T}_{12}$ & $\mathrm{~T}_{0}=>\mathrm{T}_{18}$ & $\begin{array}{l}\text { Plant specialization was delayed because } \\
\text { Alpha-Mang could not get full ownership } \\
\text { of Beta-Mang. }\end{array}$ \\
\hline $\begin{array}{l}\text { Knowledge } \\
\text { Transfer (best } \\
\text { practices sharing) }\end{array}$ & $\mathrm{T}_{0}=>\mathrm{T}_{12}$ & $\mathrm{~T}_{0}=>\mathrm{T}_{18}$ & $\begin{array}{l}\text { Knowledge transfer was delayed } \\
\text { because of temporary lay-offs and cut } \\
\text { back on travel expenses. Employees } \\
\text { could not meet to share best practices. }\end{array}$ \\
\hline
\end{tabular}

\footnotetext{
${ }^{2}$ Duration is expressed in months elapsed since the start of the acquisition in June $2008\left(\mathrm{~T}_{0}\right)$
} 
Figure A.4. An embeddedness perspective on post-acquisition integration

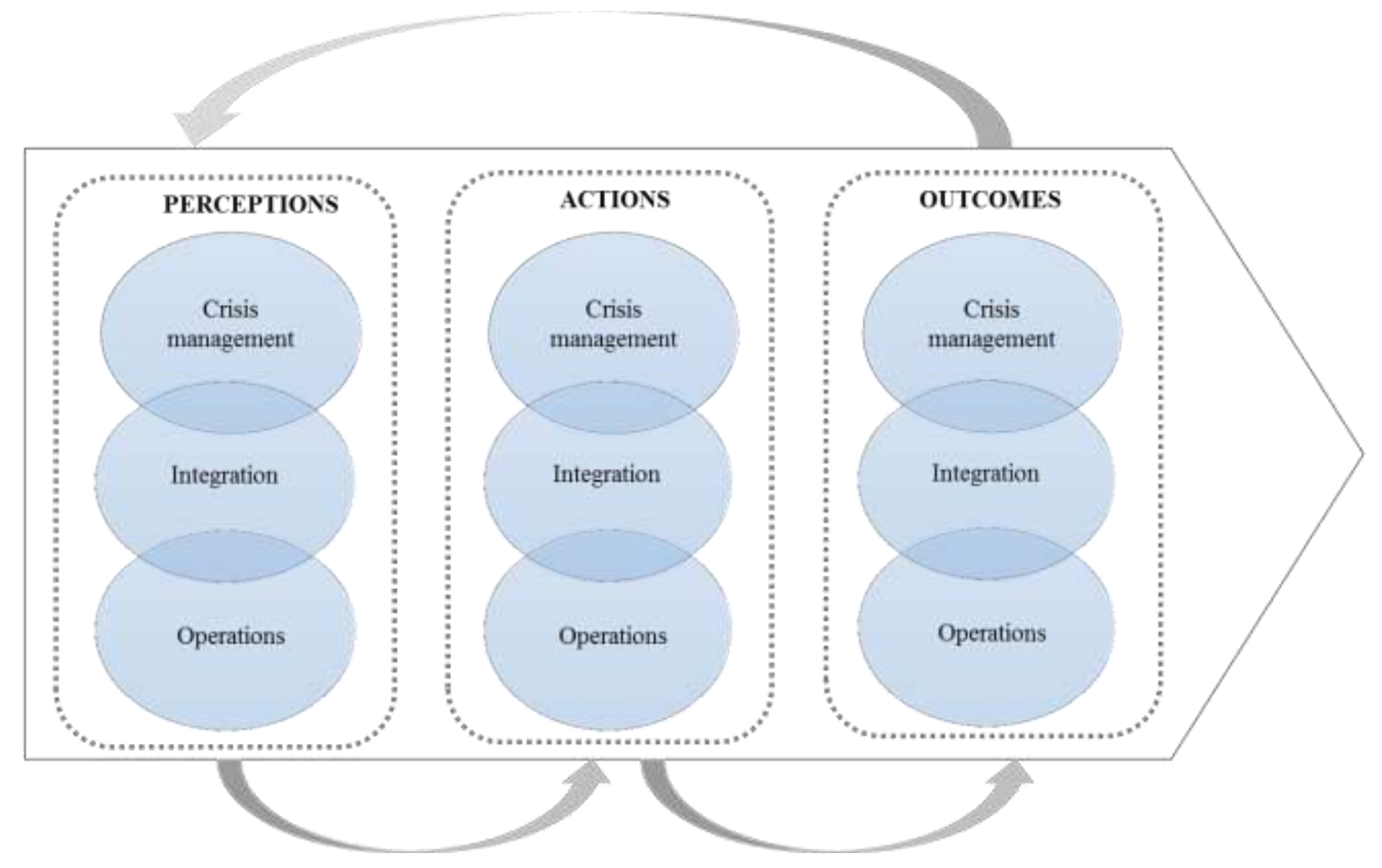


Figure A.5. The dynamic tensions of post-acquisition integration

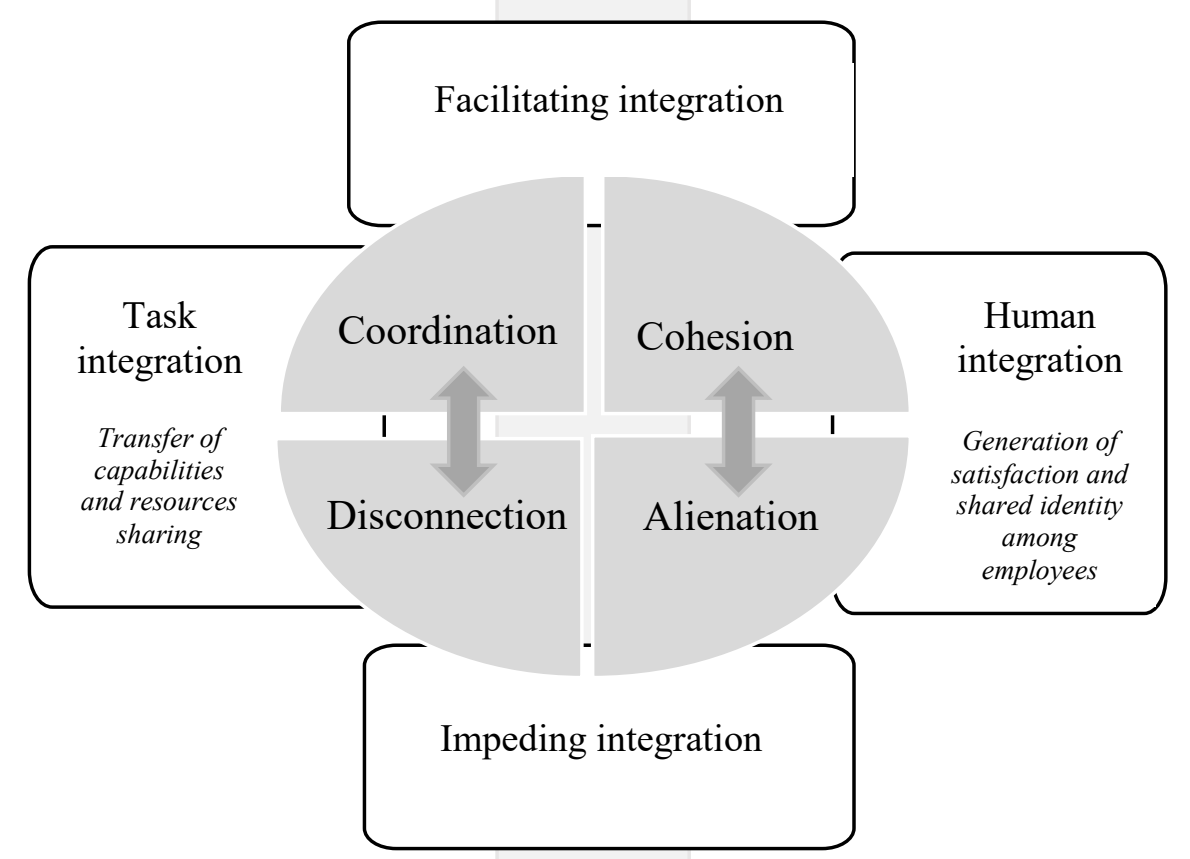

